\title{
A JUDICIALIZAÇÃO DO DIREITO À EDUCAÇÃO
}

\author{
Judicialization of the right to education
}

\author{
La judicialización del derecho a la educación
}

\author{
Ana Cláudia dos Santos Rocha* \\ Maria Alice de Miranda Aranda** \\ Paula Abrão da Cunha***
}

\begin{abstract}
Resumo
O presente artigo tem como objeto a judicialização do direito à educação pós Constituição Federal de 1988, objetivando demonstrar que embora positivado como um direito fundamental integrante do piso vital mínimo, não está garantido para todos, motivo pelo qual o Poder Judiciário tem sido acionado com o escopo de garantir sua efetividade. Assim, por meio de pesquisa bibliográfica e documental o foco foi para a legislação, para estudos afins e, por amostragem, destaca alguns julgados acerca do tema. Abordou o direito à educação e sua normatização na esfera internacional - tratados e convenções da ONU -, nacional - CF/1988, ECA 1990 e LDB/1996 e local - especificamente no município de Dourados/MS, no Plano Municipal de Educação. O estudo possibilitou constatar que em relação aos imperativos legais, o direito à educação é o horizonte e que a judicialização se apresenta como um instrumento hábil para garantir sua efetividade.
\end{abstract}

PALAVRAS-CHAVE: Direito à educação. Judicialização. Legislação.

\begin{abstract}
The present of this article is to judicialization the right to education after the Federal Constitution of 1988, as aiming of demonstrate that, although it is a fundamental right integral to the minimum vital floor it is not guaranteed for all,which is why the Power Judiciary has been scope of ensuring its effectiveness. Thus, through bibliographical and documentary research, the focus was for legislation,

\footnotetext{
* Mestre em Direito (UNIMES), Doutoranda em Educação pelo Programa de Pós-Graduação em Educação (UFGD), Professora Assistente do Curso de Direito da UFMS/CPTL, Líder do Grupo de Pesquisa "Políticas Públicas e Direitos Fundamentais", membro da Rede latino-americana e caribenha de Educação em Direitos Humanos e Membro do Grupo de Estudos e Pesquisas "Estado, Política e Gestão da Educação" (GEPGE). Email: ana.c.rocha@ufms.br

** Docente do Programa de Pós-Graduação em Educação da Universidade Federal da Grande Dourados Mestrado e Doutorado (PPGEDU/UFGD). Pós- Doutora em Educação pelo Programa Nacional de PósDoutorado/Coordenação de Aperfeiçoamento de Pessoal de Nível Superior (PNPD/CAPES) na Universidade Federal de Uberlândia (UFU). Líder do Grupo de Estudos e Pesquisas "Estado, Política e Gestão da Educação" (GEPGE). Membro do Grupo de Estudos e Pesquisas sobre Conselho Municipal de Educação no Brasil (GEPCMEBr). Integrante da Rede de Estudos e Pesquisas sobre Planejamento e Gestão Educacional (REPLAG). Email: mariaaranda@ufgd.edu.br
}

*** Mestranda em Educação pelo Programa de Pós-Graduação em Educação (UFGD). Membro do Grupo de Estudos e Pesquisas "Estado, Política e Gestão da Educação" (GEPGE). Técnica em Assuntos Educacionais na UFGD. Email: paulacunha@ufgd.edu.br 
for related studies and, by sampling, highlights some judged concerning on the theme. Approached the right to education and its normatization in the international sphere - treaties and conventions of the ONU -, national - CF / 1988, ECA 1990 and LDB / 1996 and local - specifically in the municipality of Dourados / MS, in the Municipal Plan of Education. The study made it possible to verify that in relation to legal imperatives, the right to education is the horizon and that the judicialization is presented as a skillful instrument to guarantee its effectiveness.

KEYWORDS: Right to education. Judiciary. Legislation.

\section{Resumen}

El presente artículo tiene como objeto la judicialización del derecho a la educación post Constitución Federal de 1988, con el objetivo de demostrar que aunque está positivado como un derecho fundamental integrante del piso vital mínimo, no está garantizado para todos, motivo por el cual el Poder Judicial ha sido accionado con el " el alcance de garantizar su efectividad. Así, por medio de investigación bibliográfica y documental el foco fue para la legislación, para estudios afines y, por muestreo, destaca algunos juzgados acerca del tema. Se abordó el derecho a la educación y su normatización en la esfera internacional - tratados y convenciones de las Naciones Unidas -, nacional CF / 1988, ECA 1990 y LDB / 1996 y local - específicamente en el municipio de Dourados / MS, en el Plan Municipal de Educación. El estudio posibilitó constatar que en relación a los imperativos legales, el derecho a la educación es el horizonte y que la judicialización se presenta como un instrumento hábil para garantizar su efectividad.

\section{PALABRAS CLAVE: Derecho a la educación. Legalización. Legislación.}

\section{INTRODUÇÃO}

O presente artigo tem como objeto a judicialização do direito à educação pós Constituição Federal de 1988, objetivando demonstrar que embora positivado como um direito fundamental integrante do piso vital mínimo, tal direito ainda não tem sido garantido a todos, motivo pelo qual o Poder Judiciário tem sido acionado com o escopo de garantir sua efetividade.

Ademais, urge destacar que tal direito além de previsão constitucional, também integra um rol de tratados e convenções da Organização das Nações Unidas dos quais o Brasil é signatário, bem como é objeto de legislação infraconstitucional na esfera federal, estadual e municipal.

A análise de conteúdo dos materiais pesquisados elucida hipótese inicial: que a judicialização se apresenta como um instrumento hábil para garantir a efetividade do direito à educação. Assim, por meio de pesquisa bibliográfica e documental o foco foi para a legislação, para estudos afins e, por amostragem, destacando alguns julgados acerca do tema. Abordou o direito à educação e sua normatização na esfera internacional - tratados e convenções da ONU -, nacional - CF/1988, ECA/1990 e LDB/1996 e local - especificamente no município de Dourados, no estado de Mato Grosso do Sul (MS0, no Plano Municipal de Educação (2015-2025). 
$\mathrm{Na}$ sequência a explanação se dará acerca da judicialização, enquanto instituto garantidor do direito à educação e por derradeiro, alguns julgados do Tribunal de Justiça do Mato Grosso do Sul, acerca do tema serão analisados.

\section{O direito à educação}

A educação, desde a Constituição Federal de 1988, é classificada como um direito fundamental, público e subjetivo, conforme disposto no artigo 205, in verbis: "A educação, direito de todos e dever do Estado e da família, será promovida e incentivada com a colaboração da sociedade, visando ao pleno desenvolvimento da pessoa, seu preparo para o exercício da cidadania e sua qualificação para o trabalho" (BRASIL, 1988).

Da redação do artigo 205 da Constituição Federal extrai-se o destinatário (todos) desse direito, os responsáveis em promovê-lo (Estado e família) e suas finalidades (pleno desenvolvimento da pessoa, seu preparo para cidadania e qualificação para o trabalho) (LIMA, 2009).

Ademais, ao ser positivado, via texto constitucional, como direito de todos sem quaisquer distinções, o direito humano à educação passa a integrar o rol de direitos fundamentais que devem ser garantido a todos, ou seja, deve ser garantido o acesso universal, igualitário e de qualidade ao saber e ao conhecimento, ressaltando que somente com tal direito o individuo tem condições de ser cidadão e exigir outros direitos fundamentais (DAMASCO, 2008).

E ao ser preceituado como direito de todos evidencia-se que a intenção do constituinte foi de evitar qualquer tipo de limitação a tal direito, sendo, destarte, vedada qualquer forma de discriminação, garantindo-se tal direito a grupos outrora marginalizados ou excluídos do sistema de ensino oficial tais como mulheres, negros, indígenas, deficientes etc.

A responsabilidade dos pais e do Estado em promovê-la, por seu turno, é objetiva, ensejando a obrigatoriedade de oferta-la e garantir acesso e permanência, não sendo cabível se eximir desta responsabilidade, independentemente de dolo ou culpa. Isso implica que, os pais e o Estado não podem justificar o descumprimento desta obrigação com base em falta de recursos financeiros, humanos ou qualquer outro tipo de justificativa.

Os pais e o Estado poderão ser responsabilizados - via judicial e administrativa - pela omissão ou descumprimento de tal direito, desempenhando papel significativo para tal mister a Defensoria Pública, o Ministério Público e o Conselho Tutelar.

As finalidades da educação, nos moldes explicitado pela Constituição Federal, demonstra que seu objetivo não se restringe a uma formação conteudista, atendendo tãosomente as necessidades do mercado, mas sim é voltada ao pleno desenvolvimento da pessoa, preparando-a para o exercício da cidadania e para o trabalho.

Como destaca Lima (2009), a educação não deve ser voltada apenas para o êxito econômico da pessoa, mas para torna-la capaz de interagir socialmente; valorizar a dignidade da pessoa humana - formando indivíduos que identifiquem e respeitem a dignidade alheia - e possibilitando o exercício da cidadania. 
Urge ainda destacar que o direito à educação, além dos artigos 205 a 214 da Constituição Federal, também é positivado no âmbito infraconstitucional - federal, estadual e municipal - e em tratados e convenções internacionais.

\section{Normatizações: âmbitos internacional, nacional e local}

Acerca das normatizações atinentes ao direito à educação são destaques documentos que orientam a política educacional. Em âmbito internacional, são apresentados alguns importantes tratados e convenções no âmbito das Organizações das Nações Unidas.

A Declaração Universal dos Direitos Humanos (ONU, 1948) em seu artigo 26, inclui a educação dentre os direitos humanos essenciais, preceituando sua gratuidade, obrigatoriedade - ao menos no nível fundamental - e seu papel de propiciar o pleno desenvolvimento humano e a formação para cultura de paz e respeito aos direitos humanos.

O Pacto Internacional dos Direitos Econômicos, Sociais e Culturais (ONU, 1966), estabelece no artigo 14 a obrigatoriedade e gratuidade da educação primária, sendo que o Protocolo Adicional à Convenção Americana sobre Direitos Humanos em Matéria de Direitos Humanos Econômicos, Sociais e Culturais (ONU, 1988) - Protocolo de San Salvador - no artigo 13 reforça o papel da educação formal para fortalecer o respeito aos direitos humanos, a construção de uma cultura de paz e a formação para o exercício da democracia.

Por seu turno, a Convenção sobre os Direitos da Criança (ONU, 1990), nos artigos 28 e 29 vincula os Estados-parte a garantir a obrigatoriedade e gratuidade do ensino fundamental, a expansão da oferta do ensino secundário - inclusive o profissionalizante - a acessibilidade ao ensino superior, devendo todas as modalidades de ensino fundar-se na dignidade da pessoa humana, visando erradicar o analfabetismo, desenvolver as aptidões mentais e físicas das crianças e uma formação voltada para o respeito aos direitos humanos.

Além das normatizações acima elucidadas existem outras que tratam sobre o direito à educação, versando sobre a inclusão das pessoas com deficiência, a educação no/do campo dentre outras temáticas.

Contudo, as apresentadas, a título elucidativo, sinalizam para o consenso internacional da importância da garantia do direito à educação a toda pessoa e a necessidade dos Estadosparte regulamentar tal direito no âmbito nacional com o escopo de efetiva-lo nos moldes pactuados.

No âmbito nacional, conforme dito alhures o direito à educação é garantido como direito social preceituado no Artigo $6^{\circ}$ da Constituição Federal de 1988, discorrendo nos Artigos 205 a 214, sua obrigatoriedade, gratuidade, os princípios basilares, a forma de custeio, a organização do sistema de ensino em regime de colaboração entre União, Estados, Distrito Federal e Municípios e a necessidade de normatizar, as diretrizes, objetivos, metas e estratégias para efetivação de tal direito, isso por meio de planos de educação a nível nacional (PNE), estadual (PEE) e municipal (PME) - merecendo destaque este último para o presente estudo.

Além do texto constitucional, é mister salientar que na esfera nacional o direito à educação é positivado no Estatuto da Criança e do Adolescente (ECA) - Lei n. 8.069/1990 e na Lei de Diretrizes e Bases da Educação (LDB) - Lei n. 9.394/1996. 
Do Capítulo IV do ECA, Artigos 53 a 59 extrai-se que no território nacional toda criança e adolescente tem direito de estar inserido numa escola, sendo dever do Estado ofertar ensino público, gratuito de qualidade, assegurando a matricula e a permanência destes na escola mais próxima de sua residência. Ademais, o ensino deve possibilitar o pleno desenvolvimento, preparando-os para o exercício da cidadania e qualificando-os para o trabalho, entre outros aspectos atinentes as atribuições dos dirigentes etc.

A LDB, em seus 92 Artigos define educação, apresenta os princípios que a norteiam e sua finalidade, disciplina o direito à educação e o dever de educar, organiza a educação nacional, apresentando os níveis e modalidades de educação e ensino, preceitua sobre os profissionais da educação e sobre os recursos financeiros destinados à educação.

No âmbito local, o foco do direito à educação é buscado no Plano Municipal de Dourados (2015-2025), no estado do MS. Cabe destacar que Dourados, dentre 79 municípios, é considerando o segundo município do estado, considerando aspecto populacional (área de unidade territorial do município é de 4.086.237 $\mathrm{Km}^{2}$ e 218.069 pessoas) e o aspecto econômico (a agricultura, potencial no ramo comercial e industrial, tem o título de "Portal do Mercosul)" (IBGE, 2010). A cidade tem o título de "Cidade Universitária" por comportar uma quantidade considerável no ramo, como a Universidade Federal da Grande Dourados (UFGD), a Universidade Estadual de Mato Grosso do Sul (UEMS), o Centro Universitário da Grande Dourados (UNIGRAN), a Faculdade Anhanguera de Dourados, além da unidade do Instituto Federal de Educação do Mato Grosso do Sul (IFMS) e da Faculdade de Tecnologia do SENAI (Fatec-SENAI).

O PME/Dourados (2015-2025) enquanto documento legal da gestão educacional municipal, atende as normas dadas pelo Plano Nacional de Educação (2014-2024) que no Artigo $8^{\circ}$ traz a obrigatoriedade de elaboração dos Planos Municipais de Educação, ou a adequação dos Planos dos Municípios que já os tem. Aponta como estratégia para tal empreitada a necessária articulação das políticas educacionais com as políticas sociais e a garantia de se considerar as necessidades específicas de cada local e da população. No parágrafo $2^{\circ}$ do mesmo Artigo está o indicativo de que a elaboração ou adequação desses Planos deve ser realizada com a participação "de representantes da comunidade educacional e da sociedade civil" (BRASIL, 2014).

Assim, o "[...] grande desafio da Administração Pública do Município de Dourados está em viabilizar o acesso à educação, garantia fundamental prevista na Constituição Federal, resguardando as tradições e práticas étnico-culturais desses povos" (DOURADOS, 2015, p. 13). Em linhas gerais, busca efetivar o direito à educação para todos e todas, conforme preconiza no Artigo $2^{\circ}$, dentre suas 10 diretrizes: "a promoção dos princípios do respeito aos direitos humanos, à diversidade e à sustentabilidade socioambiental".

A temática "direito" transversa por 32 vezes o PME/Dourados (2015-20125) nas suas 129 páginas, passa pelos seus 14 Artigos, 20 metas e 254 estratégias. A cada meta e conjunto de metas é apresentada uma análise situacional referente à categoria em foco ou em torno de categorias afins. São categorias do PME/Dourados: educação infantil; ensino fundamental; ensino médio; educação especial; alfabetização; educação integral; aprendizado e fluxo; escolaridade média; EJA - alfabetização; EJA - integrada e profissional; educação profissional; educação superior; titulação dos professores; pós-graduação; formação dos professores; formação continuada e pós-graduação de professores; valorização docente; plano de carreira docente; gestão democrática; financiamento e educação. 
Nos considerações iniciais do PME/Dourados, está o registro: "Muito mais do que atender a lei, é [...] usufruir o direito de ter uma educação com qualidade social" (p. 1, grifo nosso). E direito atrelado à qualidade social implica valorizar o ser humano em detrimento ao mercado (ARANDA e LIMA, 2014).

Sintetizando a presença da temática "direito" no PME/Dourados, registra-se, de antemão, afirmativas de que o direito é constitucional, fundamental à educação, assim, a educação como um direito de todos, como um direito social fundamental, que todos e todas tenham o direito à aprendizagem, o direito subjetivo à educação pública e gratuita.

Em relação à educação infantil prima pela promoção em parceria com órgãos públicos de assistência social, saúde e proteção à infância, a busca ativa de estratégias que proporcione o acesso das crianças, preservando o direito de opção da família; em todos os níveis da educação, o direito das pessoas com deficiência; no que tange à alfabetização está o direito da criança à alfabetização na idade certa e, no geral o direito ao aprendizado na idade certa, concebendo a educação como direito humano, porta de entrada para a educação, primando pelo processo de escolarização das pessoas ao longo de toda a vida. Em suma, o direito ao trabalho, a igualdade social, o respeito e a inclusão de todos no direito à cidadania plena, tudo contemplado pela efetivação do direito financeiro público.

Como se vê, a categoria "direito" é compreendida como fundamental no PME/Dourados, a questão subsequente é como garantir tal premissa e por meio de quais instrumentos.

\section{A judicialização do direito à educação}

O direito à educação, como dito alhures, é de todos, ultrapassando a dimensão individual, podendo ser exercido e exigido individualmente e coletivamente, estando incluído no âmbito da justiça distributiva, possuindo natureza de direito social, mas também de direitos civis e políticos (LIMA, 2009).

Ademais, o Poder Público para:

A consecução prática dos objetos da educação, consoante o art. 205 - pleno desenvolvimento da pessoa, seu preparo para o exercício da cidadania e sua qualificação para o trabalho -, requer que o Poder Público organize os sistemas de ensino público, para cumprir com seu dever constitucional para com a educação, mediante prestações estatais que garantam, no mínimo, os serviços consignados no art. 208 (SILVA, 2012, p. 801).

Cury e Ferreira (2009, p. 33) salientam a diferença da atual Carta Magna, com as anteriores acerca do direito a educação, discorrendo que:

Essa versão legal do direito à educação, dentro deste conjunto, não se mostrava presente nas constituições passadas, e por consequência, no ordenamento jurídico vigente. Até então, tínhamos boas intenções e proteção limitada com relação à educação, mas não uma proteção legal, ampliada e com instrumentos jurídicos adequados à sua efetivação. 
Neste sentido:

\begin{abstract}
O legislador constituinte dispensou tratamento diferenciado ao ensino obrigatório, considerando-o também como direito público subjetivo, sendo que o nãooferecimento do ensino obrigatório pelo Poder Público, ou sua oferta irregular, importa responsabilidade da autoridade competente (BRASIL, 1988, art. 208, $\S 1^{\circ} \mathrm{e}$ $2^{\circ}$ ). A LDB/96 reforça a possibilidade da exigibilidade do ensino obrigatório, "podendo qualquer cidadão, grupo de cidadãos, associação comunitária, organização sindical, entidade de classe ou outra legalmente constituída, e, ainda, o Ministério Público, acionar o Poder Público para exigi-lo" (BRASIL, 1996, art. 5) (SILVEIRA, 2011, p. 31).
\end{abstract}

Ante o arcabouço jurídico de regulamentação e tutela da educação após a promulgação da Constituição Federal de 1988 que universalizou o acesso à educação e estabeleceu mecanismo, inclusive judicias para garantir o cumprimento desta obrigação do estado e da família, possibilitando, portanto, a judicialização de tal direito fundamental.

Segundo Barroso (2016, p. 384) judicialização "significa que questões relevantes do ponto de vista político, social ou moral estão sendo decididas, em caráter final, pelo Poder Judiciário. Trata-se, como intuitivo, de uma transferência de poder para as instituições judiciais, em detrimento das instâncias políticas tradicionais, que são o Legislativo e o Executivo".

A judicialização do direito à educação pauta-se na possibilidade daqueles que se verem privados, total ou parcialmente, de tal direito, procurar as vias judiciais para exigir o cumprimento do dever do Estado de oferta-lo gratuitamente a todos.

Tendo em vista que parte dos destinatários do direito à educação se refere a hipossuficientes e vulneráveis, tais como crianças, adolescentes, deficientes, entre outros, o Poder Judiciário poderá ser acionado via individual ou coletiva, inclusive por organizações, Ministério Público e Defensoria.

Assim, judicialização "significa a intervenção do Poder Judiciário nas questões educacionais em vista da proteção desse direito até mesmo para cumprirem-se as funções constitucionais do Ministério Público e outras instituições legitimadas" (CURY e FERREIRA, 2009, p. 33). Ressaltando, ainda, os autores, que a judicialização da educação "ocorre quando aspectos relacionados ao direito à educação passam a ser objeto de análise e julgamento pelo Poder Judiciário" (Ibid., p. 35).

No que tange às hipóteses de cabimento, Lima (2009) analisa que o direito à educação integra o rol dos direitos fundamentais preceituados na Constituição Federal de 1988 e, portanto, dentro de um contexto de Estado Democrático e Social de Direito, além de determinar que o Poder Legislativo e o Poder Executivo se ocupem da realização de tal mister, possibilitam aqueles que se veem privados de tal direito que acionem o Poder Judiciário, ante a negativa ou omissão dos outros poderes, pautado à supremacia da Constituição Federal, ocasionando a judicialização das políticas públicas educacionais.

Cury e Ferreira (2009, p. 35/36) informam que o chamamento do Poder Judiciário pode se dar "por parte do próprio interessado (aluno e/ou responsável), Ministério Público, Defensores Públicos ou Conselho Tutelar", e não se limitam a garantia do acesso ao ensino de qualidade, podendo versar, por exemplo, sobre merenda escolar, transporte escolar, acessibilidade, dentre outros. 
Entretanto, como alerta Silveira (2011, p. 38):

Apesar do papel do Judiciário na educação ter se ampliado de forma expressiva, é patente a necessidade de discutir a utilização deste meio para a resolução de litígios envolvendo questões pedagógicas e educativas, pois esta instituição nem sempre será o mecanismo mais eficaz, devido ao despreparo dos seus membros para as dinâmicas envolvendo o cotidiano educacional.

Assim, urge analisar alguns efeitos da judicialização da educação, ressaltando que esta se apresenta possível pós CF/1988, sendo seu texto um marco acerca das questões educacionais ao elencar o direito à educação como um direito fundamental, estabelecendo diretrizes, princípios, fontes de custeio etc., dando assim ao tema a importância que merece.

Além de direito fundamental, a CF/1988 inclui o direito à educação no rol dos direitos sociais (Artigo $6^{\circ}$ ) integrantes do mínimo existencial ${ }^{1}$, necessário a garantir uma vida digna a qualquer pessoa e, desta forma, a ofensa a tal direito, nos moldes preceituados constitucionalmente, possibilitando àquele que for lesado em tal garantia, socorrer-se ao Poder Judiciário, mediante propositura de ações em face de quaisquer dos responsáveis pela sua concretização, "podendo ser Estado, família, sociedade e escola (educadores)" (FERREIRA, 2008, p.37), com o escopo de exigir sua prestação.

Dessa forma, o Poder Judiciário passou a agregar a função de efetivação dos direitos à educação na busca de proteção e concretização, visto que passou a ser chamado amiúde a solucionar conflitos no âmbito escolar. Dentro da literatura se pode elencar a título exemplificativo a garantia do direito a educação sob o enfoque legal nos seguintes tópicos:

(i.) Universalização do acesso e da permanência da criança e do adolescente;

(ii) Gratuidade e obrigatoriedade do ensino fundamental; (iii.) Atendimento especializado aos portadores de deficiência; (iv) Atendimento em creche e préescolas as crianças de 0 a 5 anos; (v.) Oferta de ensino noturno regular e adequado às condições do adolescente trabalhador; (vi.) Direito de contestar critérios avaliativos, podendo recorrer às instancias escolares superiores; (vii.) Acesso à escola próxima da residência; (viii) Qualidade da educação (CURY e FERREIRA, 2009, p. 35/36).

Gauri e Brinks (2008), faz uma discussão muito salutar sobre os efeitos da implementação através da via judicial das políticas públicas de educação e saúde e no estudo por eles tecido, buscam compreender inicialmente se as cortes estão se envolvendo de fato e de forma crescente no âmbito dos direitos econômicos e sociais. Em seguida, analisa a qualidade da intervenção, ou seja, se são intervenções significativas e, por fim, se a partir das determinações judiciais os governos se tornaram mais atentos às necessidades dos menos favorecidos e a partir dessas três questões eles criam o denominado por eles de "ciclo de judicialização da política pública".

\footnotetext{
${ }^{1}$ A adoção do conceito de "mínimo existencial" 'feita para possibilitar a tutela jurisdicional imediata, sem a necessidade de prévia ponderação do Legislativo ou do Executivo por meio de política específica, e sem a possibilidade de questionamento, em juízo, das condições práticas de sua efetivação, vale dizer, sem sujeição à cláusula da "reserva do possível” (WATANABE, 2013, p. 218).
} 
Ainda, segundo Gauri e Brinks (2008), as determinações do Poder Judiciário sobre o Executivo não afetam somente o caso discutido na ação, mas o processo de políticas públicas como um todo, incluindo a formulação, ou reformulação no caso de revisões legislativas, afetam a implementação, ou seja, se o governo levou em conta ou não a decisão para as próximas tomada de decisão, além de influenciar na própria avaliação da politica.

Ximenes, Oliveira e Da Silva (2017) elencam, ainda, quatro efeitos que podem ocorrer e incluem primeiramente a ampliação "na garantia do direito e no acesso à justiça", em seguida, uma adequação "financeira e administrativamente" na busca da resposta a ser dada a judicialização (conforme demonstraram Wang et al., 2015, no caso da saúde). Elencam, também, forma de resposta que pode ser "por meio da discussão de legislações especificas quanto pode ampliar a fiscalização do Executivo na garantia do direito à educação infantil, inclusive pela mobilização dos respectivos Tribunais de Contas" e finalmente, Rizzi e Ximenes (2014) analisam a participação e o controle social, e o acompanhamento das decisões por ele proferidas.

Ante o protagonismo do Poder Judiciário acerca das questões educacionais, propõe-se analisar - por amostragem - alguns julgados na esfera do Tribunal de Justiça do Estado de Mato Grosso do Sul (TJMS), em específico de ações oriundas da comarca de Dourados, MS.

Para tanto, em 13/04/2018, procedeu-se a busca no sítio eletrônico do TJMS pelo endereço eletrônico http://www.tjms.jus.br., utilizando a opção "consultas" e entrando na sessão "consulta de jurisprudência do Tribunal de Justiça e das Turmas recursais - Digital" e no link "consulta completa", com isso incluindo como discriminante a palavra "direito a educação" marcando nos campos específicos da pesquisa os "julgados de origem $2^{\circ}$ grau" e "turmas recursais", no tipo de publicação incluindo os "acórdãos", as "homologações de acordo" e as "decisões monocráticas" e "ordenado por data de publicação". Inicialmente não colocou-se data especifica para verificar quantas decisões surgiriam da busca.

Considerando que o site não possui a opção para procurar por cidade, foram encontrados 414 acórdãos, 0 homologação de acordos e 26 decisões monocráticas no Estado de Mato Grosso do Sul. Dessas decisões foi necessária a leitura de cada uma delas para determinar a cidade a qual pertence o processo.

Das decisões encontradas, 6 processos eram relativos a cidade de Dourados. Dessas decisões 2 tratavam de assuntos que não versavam especificamente sobre educação mas tangiam sobre pensão de matriculados, portanto foram suprimidas tais decisões.

Relativo a decisões monocráticas relativas à cidade de Dourados, urge analisar a Apelação $n^{\circ}$ 0801581-84.2012.8.12.0002:

- $\quad$ EMENTA- apelação cível- ação de obrigação de fazer - matrícula em escola mais próxima de sua residência - pedido atendido pela administração em data anterior à sentença - fato superveniente caracterizado - direito garantido à educação - sentença mantida - recurso improvido.

Em análise:

O direito a educação é garantia constitucional da criança e do adolescente, e constitui dever do Estado disponibilizar vagas em unidades de ensino para atender os interesses da criança. Demonstrado que foi disponibilizada vaga em unidade escolar mais próxima da residência do autor, antes da prolação da sentença e sem a necessidade de determinação judicial, caracteriza-se o fato superveniente que importa na perda do objeto da ação. Recurso conhecido e improvido, nos termos do 
art. 557 caput, do CPC. (TJMS, AP nº 0801581-84.2012.8.12.0002. Relator: Des. Dorival Renato Pavan, Data do Julgamento: 01/07/2013, 4 ${ }^{a}$ Câmara Cível, Data da Publicação: 04/07/2013).

$\mathrm{Na}$ apelação acima, se discutiu o direito à matricula de aluno em estabelecimento mais próximo da residência, conforme preceituado pela legislação federal. Entretanto, extrai-se da decisão um fato superveniente, que ocasionou a perda do objeto da ação, qual seja, a administração pública municipal garantiu a vaga nos moldes solicitado na ação, antes da prolação da decisão. Sendo assim, garantido o direito à educação ao autor da ação nas condições preceituadas pela legislação infraconstitucional.

Interessante notar que a administração pública ofereceu a vaga solicitada pelo autor que antes do ajuizamento da ação havia negado - ante a judicialização da celeuma, demonstrando, dessa forma um aspecto positivo da judicialização. Por vezes, a administração pública só cumpre com suas obrigações determinadas em lei, após a interferência do Poder Judiciário.

Já na aba acórdãos, encontramos três processos:

$1^{\circ}$ - E M E N T A - reexame de sentença - mandado de segurança - indeferimento da matrícula de criança em centro de educação infantil por falta de vagas - direito à educação indisponibilidade - direito assegurada pela constituição da república, pelo estatuto da criança e do adolescente e pela lei de diretrizes e bases da educação nacional - violação a direito líquido e certo - ordem concedida - sentença confirmada. (TJMS, RS. n. 081051038.2014.8.12.0002. Relator: Des. José Ale Ahmad Netto, Data do Julgamento: 13/05/2015. $2^{\mathrm{a}}$ Câmara Cível. Data da publicação: 15/05/2015).

$2^{\circ}$ - E M E N T A - agravo de instrumento - ação de obrigação de fazer - liminar deferida - matrícula na pré-escola - crianças que venham a completar 4 anos no decorrer do ano letivo - preliminares - ausência de peça obrigatória - incompetência da vara da infância e juventude - ilegitimidade ativa - afastadas - decisão mantida - negado provimento ao recurso (TJMS, AI. N. 0024751-27.2012.8.12.0000, Relator: Des. Fernando Mauro Moreira Marinho. Data do julgamento: 22/05/2012. $3^{\text {a }}$ Câmara Cível. Data da Publicação: 31/05/2012).

O primeiro se trata de Mandado de Segurança onde se buscava a matricula de criança em Centro de Educação Infantil, que foi garantido com a judicialização. Insta observar que o mandado de segurança esta preceituado no artigo $5^{\circ}$, LXIX e LXX da Constituição Federal e na Lei n. 12.016/2009, cabível quando se constata que o Poder Público violou direito líquido e certo, como o caso analisado, o direito a vaga em centro de educação infantil é direito público, subjetivo e fundamental, não sendo passível de ser negado sob o argumento da falta de vaga, uma vez que é obrigatoriedade do estado oferta-la a todos, sem distinção ou limitação.

Por integrar o mínimo existencial, a matrícula em centro de educação infantil não pode ser negada sob o argumento de falta de vaga, tendo em vista que a teoria da reserva do possível não se aplica na situação fática, sendo inquestionável sua obrigatoriedade, incabível qualquer justificativa para limitar ou excluir tal direito.

O Tribunal de Justiça de Mato Grosso do Sul, acertadamente manteve a decisão de primeira instância que garantiu ao autor da ação o exercício de seu direito à educação, mostrando novamente como o Poder Judiciário pode interferir positivamente na efetivação dos direitos fundamentais e sociais, tal como no caso em tela. 
O segundo se trata de Ação de Obrigação de Fazer onde buscava a matricula na préescola de criança com 3 anos, mas que completaria 4 anos no decorrer do ano letivo. Percebese que a discussão circunda acerca da data corte utilizada por algumas redes de ensino para estipular uma data limite para efetivação da matricula. Inicialmente a decisão do juízo de primeiro grau concedeu o direito o que motivou o poder público municipal (Dourados) a ingressar com recurso, o qual restou infrutífero, sendo mantido o direito a matricula ao menor.

Percebe-se no presente caso que a administração pública procura limitar com normativa local o acesso a educação infantil, com base tão somente em critério cronológico. Insta salientar que inúmeras ações nesse sentido foram ajuizadas em todo território nacional após a reestruturação do ensino fundamental pela Lei n. 11.274/2006, que alterou os artigos 29, 0, 32 e 87 da LDB (Lei n. 9.394/96), que passou a ter 9 anos, afetando a organização da educação infantil também.

Sobre o assunto o Conselho Nacional de Educação (CNE) e a Câmara de Educação Básica (CEB) emitiu o Parecer n. 18/2005, com orientações acerca da matrícula. Assim, a estipulação de data de corte, como no caso em tela, fere os artigos 205, caput s e 208, V da $\mathrm{CF} / 1988$.

$\mathrm{E}$, finalmente, na decisão in verbis:

$3^{\circ}$ - E M E N T A - recurso obrigatório - pedido de vaga em creche negado direito à educação - dever do município - ato ilegal - afronta ao direito constitucional à educação - direito liquido e certo a ser amparado pela via mandamental - recurso obrigatório desprovido (TJMS. RO. N. 0804288-59.2011.8.12.0002. Relator: Des. Júlio Roberto Siqueira Cardoso. Data do Julgamento: 02/02/2012. $5^{\text {a }}$ Câmara Cível. Data da Publicação: 07/02/2012).

Constata-se neste último pedido de vaga em creche - denominação correta a época, hoje centro de educação infantil - que foi concedido pelo Poder Judiciário. Acertadamente o Poder Judiciário impeliu a administração municipal a garantir o acesso à educação, na modalidade educação infantil ao impetrante, pois conforme dito alhures tal direito fundamental é obrigatório, não podendo o Poder Público eximir-se da prestação à guisa de qualquer pretexto.

\section{CONSIDERAÇÕES FINAIS}

As contribuições possibilitadas pelo estudo em pauta e relacionadas aos conhecimentos angariados à temática oportunizam tecer discussão sobre a imprescindibilidade da efetivação, de fato, do direito à educação como premissa fundamental ao projeto de sociedade que se almeja concretizar.

Entretanto, tal premissa não é universal, mesmo prevista constitucionalmente, integrando um rol de tratados e convenções, do internacional ao local, ficou evidente a necessária presença do Poder Judiciário com o escopo de garantir sua efetividade, o que justifica o tema em questão: a judicialização do direito à educação.

Evidência pode ser observada na análise de processos apresentados que versavam sobre o "direito a educação" e que, após filtragem para o município de Dourados, se percebe 
que a judicialização teve efeitos positivos aos jurisdicionados, resultando na efetivação do direito à educação àqueles que tiveram seu direito violado pela administração municipal, demonstrando ser a judicialização um instrumento hábil para garantir tal direito.

Em suma, o estudo possibilitou constatar que em relação aos imperativos legais o direito à educação é o horizonte e que a judicialização se apresenta como um instrumento hábil para garantir sua efetividade, considerando os interstícios sociais, políticos e econômicos de uma dada sociedade.

\section{REFERENCIAS}

ARANDA, M. A. de M.; LIMA, F. R. O Plano Nacional de Educação e a Busca pela Qualidade Socialmente Referenciada. Educação e Políticas em Debate, v. 3, 2014. p. 291313.

BARROSO, L. R. O controle de constitucionalidade no direito brasileiro: exposição sistemática da doutrina e análise crítica da jurisprudência. 7. ed.. rev. e atual. São Paulo: Saraiva, 2016.

BORGES, M. S. V. A atuação do sistema de justiça na efetivação dos direitos fundamentais: um estudo sobre o direito à educação básica, a comarca de Florianópolis/SC, no período de 2000-2005. Dissertação (Mestrado em Direito) - Universidade Federal de Santa Catarina. Florianópolis: 2007. 230 p.

BRASIL. Declaração dos Direitos Humanos. Disponível em: $<$ http://www.brasil.gov.br/cidadania-e-justica/2009/11/declaracao-universal-dos-direitoshumanos-garante-igualdade-social>. Acesso em: 23/06/2018.

BRASIL. Decreto n ${ }^{\circ}$ 99.710/1990. Convenção sobre os Direitos da Criança. Disponível em: <http://www.planalto.gov.br/ccivil_03/decreto/1990-1994/D99710.htm>. Acesso em: 23/06/2018.

BRASIL. Decreto $n^{\circ}$ 591/1992. Pacto Internacional sobre Direitos Econômicos, Sociais e Culturais. Disponível em: <http://www.planalto.gov.br/ccivil_03/decreto/19901994/d0591.htm>. Acesso em: 23/06/2018.

BRASIL. Decreto 3321/1999. Protocolo Adicional a Convenção Americana sobre Direitos Humanos em Matéria de Direitos Economicos, Sociais e Culturais. Disponível em: <http://www.oas.org/juridico/portuguese/treaties/a-52.htm>. Acesso em: 23/06/2017. 
BRASIL. Lei no 9.394/1996. Lei de Diretrizes e Bases da Educação Nacional. Disponível em: <http://www.planalto.gov.br/ccivil_03/leis/L9394.htm>. Acesso em: 23/06/2018.

BRASIL. Lei $N^{o}$ 13.005, de 25 de junho de 2014. Aprova o Plano Nacional de Educação (2014-2024). Brasil, 2014. Disponível em: <http://www.planalto.gov.br/ccivil_03/_ato2011 2014/2014/lei/113005.htm>. Acesso em: 03/2018.

CURY, C. R. J.; FERREIRA, L. A. M. A judicialização da educação. Revista CEI. Brasília. Ano XIII. n. 45. p. 32-45. abr-jun. 2009

DAMASCO, D. G. de B. O direito à educação: atuação das Promotorias de Justiça e de Defesa do Ministério Público do Distrito Federal e Territórios, entre 2001 e 2007. 199 p. Dissertação (Mestrado em Educação) - Universidade de Brasília. Brasília: 2008.

DOURADOS. Lei $n^{\circ} 3.904$ de 23 de junho de 2015. Aprova o Plano Municipal de Educação do Município de Dourados do Estado do Mato Grosso do Sul, e dá outras providências. Dourados, MS, 2015. Disponível em: <http://www.dourados.ms.gov.br/wpcontent/uploads/2015/11/PME-Dourados-2015-Vers\%C3\%A3o-Final-1.pdf〉. Acesso em: 29/10/2017.

FERREIRA, L. A. M. O Estatuto da Criança e do Adolescente e o professor: reflexos na sua formação e atuação. São Paulo: Cortez, 2008.

GAURI, V.; BRINKS, D. M. Courting Social Justice: judicial enforcement of social and economic rights in the developing world. Cambridge: Cambridge University Press, 2008.

IBGE. Instituto Brasileiro de Geografia e Estatísticas. Disponível em: $<$ https://cidades.ibge.gov.br/brasil/ms/dourados/panorama>. Acesso em: 01/2018.

LIMA, I. B. de. A exigibilidade judicial do direito fundamental à educação na Constituição Federal de 1988. Dissertação (Mestrado em Direito) - Universidade Federal do Pará. Belém: 2009. $140 f$.

SILVA, J. A. da. Curso de Direito Constitucional Positivo. 35. ed. São Paulo: Malheiros Editores Ltda., 2012. 
SILVEIRA, A. A. D. Judicialização da educação para a efetivação do direito à educação básica. Jornal de Políticas Educacionais, n. 9, jan.-jun./2011. Pp. 30-40

TRIBUNAL DE JUSTIÇA DE MATO GROSSO DO SUL. AP $n^{\circ}$ 080158184.2012.8.12.0002. Relator: Des. Dorival Renato Pavan, Data do Julgamento: 01/07/2013, $4^{\mathrm{a}}$ Câmara Cível, Data da Publicação: 04/07/2013.

TRIBUNAL DE JUSTIÇA DE MATO GROSSO DO SUL. $R S . \quad n$. 081051038.2014.8.12.0002. Relator: Des. José Ale Ahmad Netto, Data do Julgamento: 13/05/2015. $2^{\mathrm{a}}$ Câmara Cível. Data da publicação: 15/05/2015.

TRIBUNAL DE JUSTIÇA DE MATO GROSSO DO SUL. AI. n. 002475127.2012.8.12.0000, Relator: Des. Fernando Mauro Moreira Marinho. Data do Julgamento: 22/05/2012. $3^{\text {a }}$ Câmara Cível. Data da Publicação: 31/05/2012

TRIBUNAL DE JUSTIÇA DE MATO GROSSO DO SUL. $R O$. $n$. 080428859.2011.8.12.0002. Relator: Des. Júlio Roberto Siqueira Cardoso. Data do Julgamento: 02/02/2012. 5ª Câmara Cível. Data da Publicação: 07/02/2012

XIMENES - UFABC, S. B.; OLIVEIRA - UFABC, V. E.; SILVA-UFABC, M. P. Judicialização da Educação Infantil: efeitos da Interação entre o Sistema de Justiça e a Administração. $38^{\text {a }}$ Reunião Nacional da ANPEd - 01 a 05 de outubro de 2017 - UFMA São Luís/MA. 2017

WANG, D. W. L. et al. Os impactos da judicialização da saúde no município de São Paulo: gasto público e organização federativa. RAP, v. 48(5), p. 1191-120, 2015.

Recebido em: 10/02/2018

Aceito em: 04/04/2018 